How to Cite

Al-Ayubi, S. (2019). Strategy on providing health internet services for community. International Journal of Physics \&

Mathematics, 2(1), 11-20. https://doi.org/10.31295/ijpm.v2n1.78

\title{
Strategy on Providing Health Internet Services for Community
}

\author{
Sholahudin Al-Ayubi \\ Universidad Tecnica de Manabi, Portoviejo, Ecuador \\ Email: sholahudin@gmail.com
}

\begin{abstract}
Praise the author turning to the presence of God Almighty, who was willing to provide guidance and strength to the author so that paper, "Internet Service Provider (ISP)" can be resolved. This paper was prepared and was made based on the material-the material. Material-material aims to gain knowledge and insight into learning information and communication technology. And also can understand the value-the value reflected in the basic thinking and acting. Hopefully by learning this paper, will be able to face the problems or difficulties that arise in learning Internet technology. And with the hope that is able to innovate and be creative with the potential.
\end{abstract}

Keywords---innovate, internet, ISP, learning, technology.

\section{Introduction}

Internet (short -networking interconnection ) literally is a global system of an entire network of computers connected together using the standard Internet Protocol Suite ( TCP / IP ) to serve billions of users worldwide (Fernández et al., 1999). When the Internet (the letter 'I ' large) is a common computer system, which connects globally and using TCP / IP as the protocol of packet switching (packet switching communication protocol). The largest Internet circuit called the Internet. Many ways are used to connect to the Internet (Błachnio et al., 2015). One of them using ISP.

Formulation of the problem

1) How to choose the company ISP?

2) What Is The Definition and History of ISP?

3) Any software that is used to connect to the internet?

Aims

1) Knowing how to select an ISP

2) Knowing Definition and History of ISP

3) Mention example of the application of the ISP for society healthy

\section{Discussion}

Internet Service Provider (ISP)

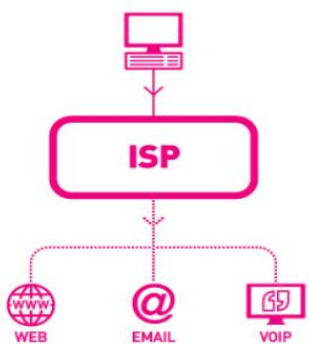

Figure 1. Internet Service Provider

ISSN 2632-9417

Received Jan 20, 2019 / Accepted Jun 18, 2019 / Published Jul 05, 2019 


\section{Understanding the Internet Service Provider}

In general, Sardini et al., (2010), the internet services provider or ISP are those who engage in internet service provider which is often also referred to as ISPs. Company or organization providing internet access connection services both for individuals, offices, campuses, schools, and so forth. In Indonesia alone has so far stood several internet service providers, some examples of ISPs in Indonesia, among others, is Telkom Speedy, SmartFren, Indosat and others (Kraus et al., 2010; Pereira, 2014).

The ISP has network both domestically and internationally so that the customer or user of the connection provided by the ISP to connect to the global Internet network. Network here in the form of a transmission medium that can stream data that can be either wired (cable modem rental, and broadband), radios and VSAT.

In Indonesia, it is handled by APJI (Internet Service Providers Association). His company is commonly called ISP (Internet Service Provider). Things that are usually done by the ISP is the provision of the IP address (IP address) to its customers and their public regarding bandwidth settings (Gackenbach, 2011; Madan et al., 2002). Roughly speaking, the bandwidth can be interpreted as a highway. The larger the way, your internet activity would be more smooth, determined by the size Kbps or KBps which is a measure of data transfer speed. Even now it is a matter Mbps or even Giga. Monitoring is done by one part in ISP called NOC (Network Operation Center).

\section{The function and role of the ISP}

a) The Role of ISP

Role of ISPs in internet access among others:

1) As a media that provides services to connect to the internet

2) Connecting customers to the nearest internet gateway.

3) Provide a modem for dial-up.

4) Connecting a user to the information service World Wide Web (www).

5) Allows a user to use the service of electronic mail (email)

6) Allows a user to conduct voice conversations via the internet.

7) Provide a place for the homepage.

8) ISP to protection from the spread of the virus by applying antivirus systems for its customers

b) ISP Function

As a company that offers services to connect to the internet. To access, we simply call the ISP via computer and modem. Then, the ISP will take care of everything needed to connect to the internet.

\section{History ISP}

Before the Internet existed, ARPAnet (US Defense Advanced Research Projects Agency) or the US Department of Defense in 1969 to make computer networks scattered to avoid the occurrence of centralized information, which in the event of war can be easily destroyed. So when one part of the network connection is interrupted from enemy attack, the path through the connection has automatically moved another outage. After that, the Internet is used by academics (UCLA) for research and technological development. And only after that the United States Government to grant permission to the commercial direction in the early 1990s (Ustinavičienè et al., 2016).

Beginning in the decade of the 90s the development of the Internet is growing rapidly, in Indonesia alone business Internet began to be known around the 95's which begins with the advent of the Internet Service Provider that provides access to the Internet with a bandwidth ranging from $14.4 \mathrm{kbps}$ to $28.8 \mathrm{kbps}$. By the end of 1999 a list of ISPs in Indonesia either already in operation or not in operation about 55 ISPs, but this time in the year 2001 the overall number of ISPs recorded in the Indonesian Internet Service Provider Association (APJII) has stepped number 155 ISP (Myers \& Turvey, 2012).

ISP is the first time in Indonesia is IPTEKnet fully operational by the beginning of 1994. In the 1994's began operating IndoNet led by Sanjaya. IndoNet is the first commercial ISP Indonesia at that time did not know about the POSTEL crevices Internet business and still very few Internet users in Indonesia. As I recall the initial connection to the Internet using dial-up done by IndoNet, a move that perhaps desperate enough. Location IndoNet still in the area Rawamangun in complex UI lecturer chance Sanjaya's father is a lecturer at UI. As we know that the development of the Internet business venture in Indonesia increasingly prevalent with 60s ISPs that obtain a license from the government. ISP Association (APJII) formed hatched by Sanjaya cs in the 1998's. Efficiency connection between the ISP continues to be done by building several Internet Exchange (IX) in Indosat, Telkom, APJII (IIX) and several 
other ISPs that mutual exchange. APJII even started to maneuver to increase the market share of the Internet in Indonesia by doing SMU2000 program that evolved into School 2000 (Neinstein, 2000).

\section{Types of ISP services can usually be categorized into two parts}

\section{The dial-on-demand Internet}

The dial on demand is internet service where customers are not continuously connected to the internet. Customers will be charged based on the length of time they connect to the internet service internet. Sampling dial on demand is Telkomnet instant of Telkom, dial-up services from other ISPs, as well as some services from local wireless ISP.

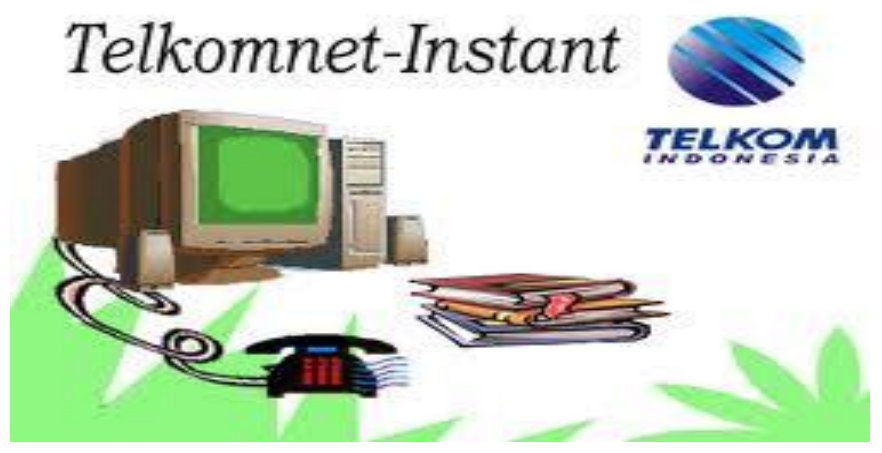

Figure 2. Example Dial on Demand Internet

\section{Dedicated Internet}

Customers who use a dedicated internet will be connected continuously to the Internet 24/7. The payment system of the service is also usually done per month where customers will pay according to the packages offered, either during the month users were indeed using the internet 24 hours a day or not.

These dedicated systems are usually expensive, and usually, to reduce the cost of subscriptions, ISP provides several methods to suppress the price, for example by limiting the amount of data to be downloaded and uploaded by customers for 1 month. Limit the number of data is typically called a dedicated internet service quota. Example internet is services of Channel 11, ERA ACCESS, Speedy from Telkom and services from local wireless ISP.

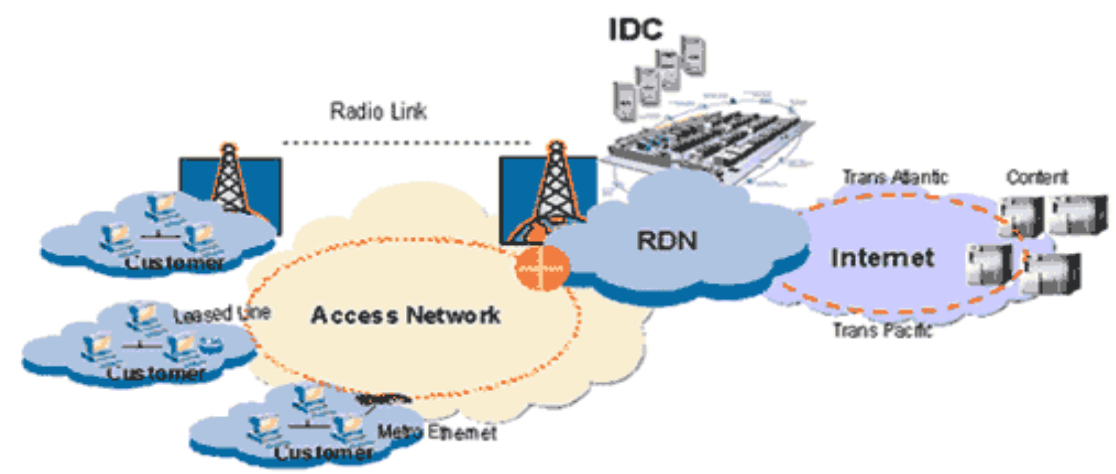

Figure 3. Local wireless ISP

Media connections are most commonly used by ISP is using

Wire (cable)

Cable. Telephone cable, coaxial cable, fiber optic cable, power cable, UTP cable, cable anyway. Internet access turnnumber or in English is called a dial-up connection is the term information technology in the English language that refers to access the Internet by using a fixed telephone line or mobile phone. First of all, the computer via modem to 
call a phone (dial-up) to the Internet Service Provider. Once connected, the computer can quickly access the Internet and then end the connection by disconnecting the phone.

There are still many people who use the service Dial-up is due to inability to get high-speed relations services (high-speed Internet connection), due to limited funds and geographic areas. To do Dial-up Connection, devices are needed as follows:

1) Hardware

a) Komputer

b) Modem

c) Telepon Line

2) Software: generally provided by the ISP which we subscribe.

3) User name and password: provided by ISP which we subscribe, login password can not be replaced while we can replace themselves regularly to maintain security. What we need to do is:

a) A subscription to one of the nearest ISP

b) Install a modem to our computer

c) Installing Internet software provided by ISP

d) Connect yourself ( dial-up ) to ISP

4) Once the computer is connected to the ISP, the same time the computer is able to connect to the Internet and we can start browsing on the Internet. Connection to the Internet only existed for maintaining our computer's connection to the ISP through a modem. Once we disconnect the modem to the ISP then when it also computer disconnected from the Internet.

5) The relationship that we do to the ISP is a local connection (using a local telephone cost), but we can already browse the Internet and visit other places around the world. Surely 'visits' us to other places that are virtual (unreal) because we can only see the information that is contained in other computers around the world connected to the Internet. Because it is virtual, the Internet is known as cyberspace (cyberspace).

6) Dial-up Connection is generally used by individuals who want to access the Internet from home. Computers are used for dial-up generally is a single computer (not a computer network)

7) Examples of connecting via ISP "Instant TelkomNet"

8) In connecting to the Internet, there are some steps taken by the computer.

9) Verifying Username

10) Handshaking

11)Connecting

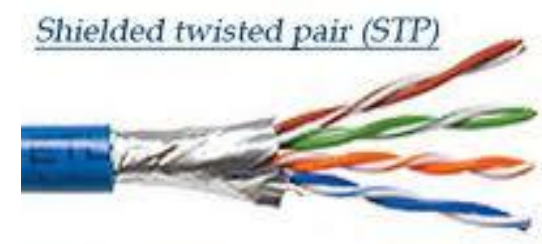

$\underline{\text { Unshielded twisted pair (UTP) }}$

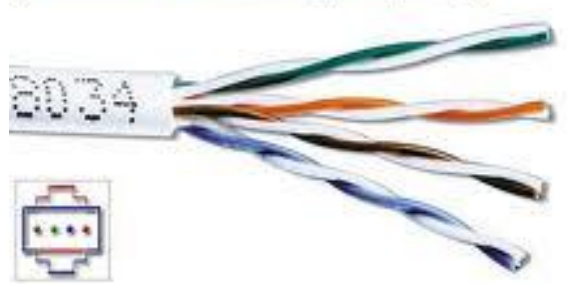

Figure 4. Cable of Utp and STP

\section{Wireless}

Do not use a lot of wires. Cables remain in use, but most of the connection point using frequency. Usually, use frequencies freed for use in a country. In Indonesia, free frequency used is $2.4 \mathrm{GHz}$ frequency. So the customer will use $2.4 \mathrm{GHz}$ wireless radio frequency to connect with their ISP. 
Internet Protocol (IP) is the method or protocol to transmit data to the Internet. Each computer (usually called the host) on the Internet at least must have a unique IP address that identifies the computer to other computers. When you send or receive data (eg, email or website), the message will be divided into several packages. Each packet contains the sender's IP and IP receiver. Gateway who will receive it directly forwards to the destination via the best path found while considering IP sender and receiver. Because the message is divided into packets and can be received out of sequence at the destination, IP will never notice, just send it. TCP (Transmission Control Protocol) which will be put in the correct order.

Search Engine is a program used to search for information in a specific environment and stores it in a database. The term is often too linked to Internet search engines, the search engine designed specifically to search for information on the Internet. Actually, search engine can also be used to search offline content such as library catalogs, the content of hard drives in personal computers, or catalogs of museum collections and so on. Search engines help us organize and display information such that the information is easily accessible. Examples of each ISP and IP as well as search engines that exist today!

Sample ISP $\quad$ : (Telkomnet Instant And Telkom Speedy from Telkom, Wireless)

Sample IP : : $\quad$ : (192.168.0.3./ 192.168.0.10)

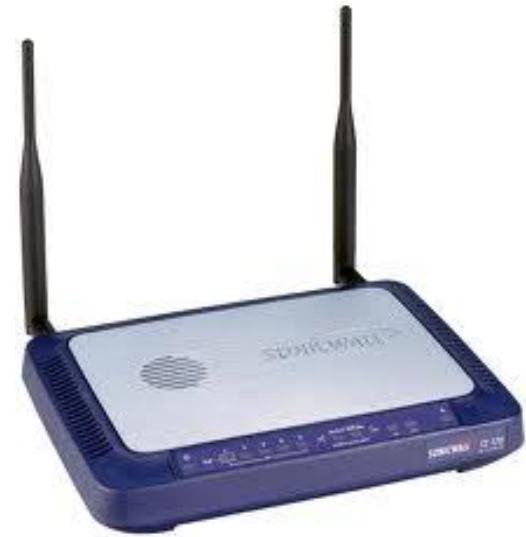

Figure 5. Example modem Wirelles

ISPs implement a monthly fee to the customer. This relationship is usually divided into two categories, namely:

The line width (Broadband)

There are different types of broadband Internet connections, depending on cost, speed, and availability. It is as follows:

a) ADSL (Asymmetric Digital Subscriber Line)

ADSL is the most commonly used broadband internet connection. It is widely used for residential and commercial. ADSL is a digital line that can be used to access the Internet without disrupting your phone line. ADSL works at a speed of $512 \mathrm{kbps}$ or higher. ADSL enables high-speed internet connection without your phone line busy. Free download is bigger than the upload speed, in the case of an ADSL connection. It is called ' asymmetric ' because of this difference in download and upload speeds.

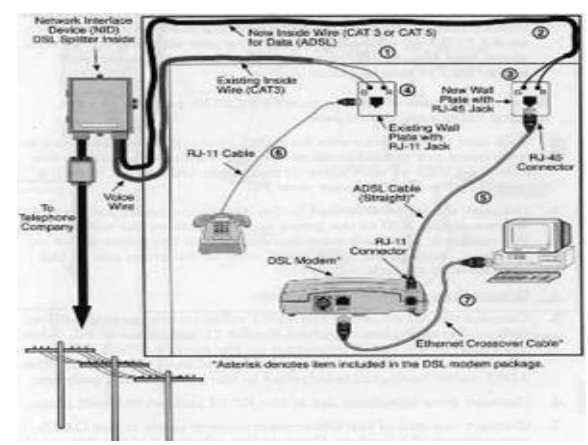

Figure 6. ADSL 
b) SDSL (Symmetric Digital Subscriber Line)

SDSL is equal to ADSL, differ only in one aspect, the upload speed. The SDSL broadband internet connection is characterized by identical upload and download speeds. It is beneficial for commercial and business purposes as required upload speed is high, and SDSL connections fulfill this requirement. It is more expensive than ADSL but worth the cost as a business and commercial benefits to be considered.

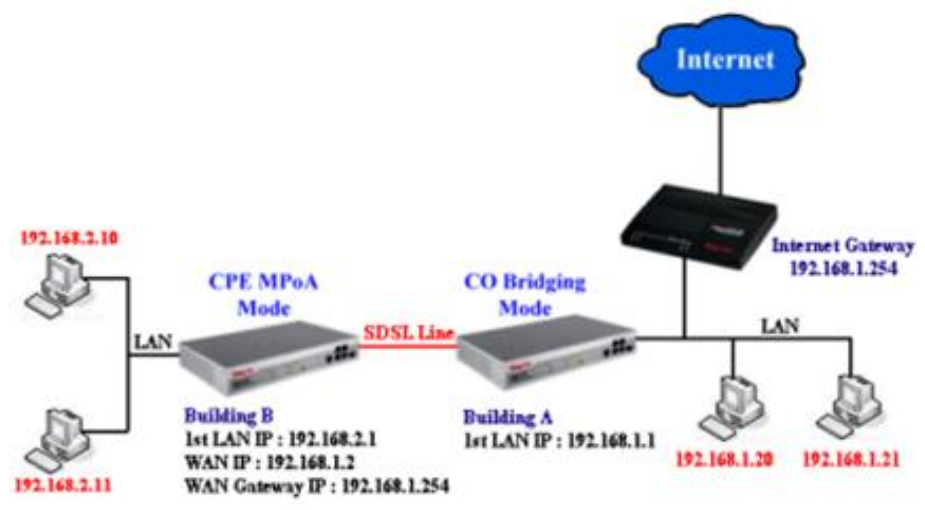

Figure 7. SDSL

1) Wireless Broadband Internet Connection

Wireless internet connection is a connection we need now is laptops, palmtops, and mobile phones, all have a wireless internet connection. Free download is provided by the type of broadband Internet access technologies ranging from $128 \mathrm{kbps}$ to $2 \mathrm{Mbps}$. This technology is growing due to the increasing use of wireless devices such as mobile phones and laptops.

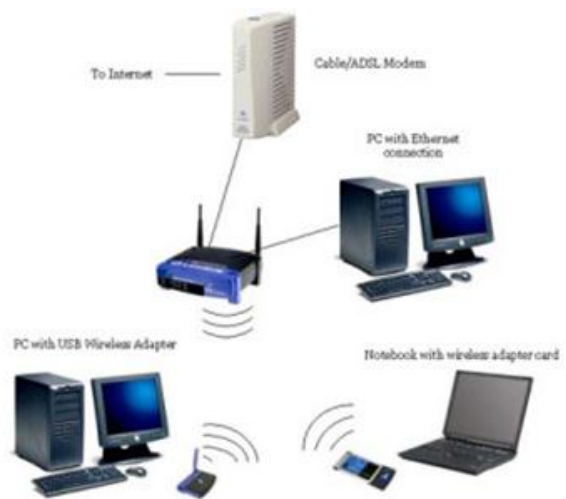

Figure 8. Wireless Broadband

2) Cable Broadband Internet Connection

The Internet can be accessed via the cable TV connection. Cable TV is used by almost everyone and now the internet connection was also made available together with cable channels. Cable broadband internet connection provides speeds ranging from $2 \mathrm{Mbps}$ to $8 \mathrm{Mbps}$. The connection is widely used in residential areas. It is more popular than ADSL internet connection, although the download and upload speeds of both types of the same broadband internet connection 


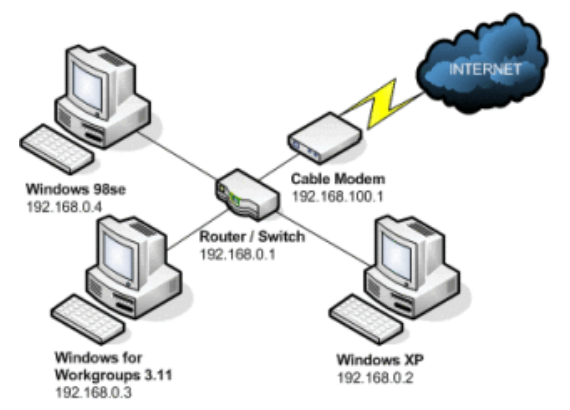

Figure 9. Cable Broadband

3) Satellite Broadband Internet Connection

All forms of broadband internet connection described above have

a limited area, which is the area that may hinder the signal emitted from the tower as in urban areas or mountains. Satellite broadband internet connection is the solution to this problem. In this type of Internet connection, which geostationary satellites to provide Internet access. Need a satellite dish and other supporting hardware necessary to receive the signal. The speed offered by satellite internet connection is 2 Mbps for download and 1 Mbps for uploads.

This speed is less compared to other types of broadband internet connections and weather affect the signal for the most part.

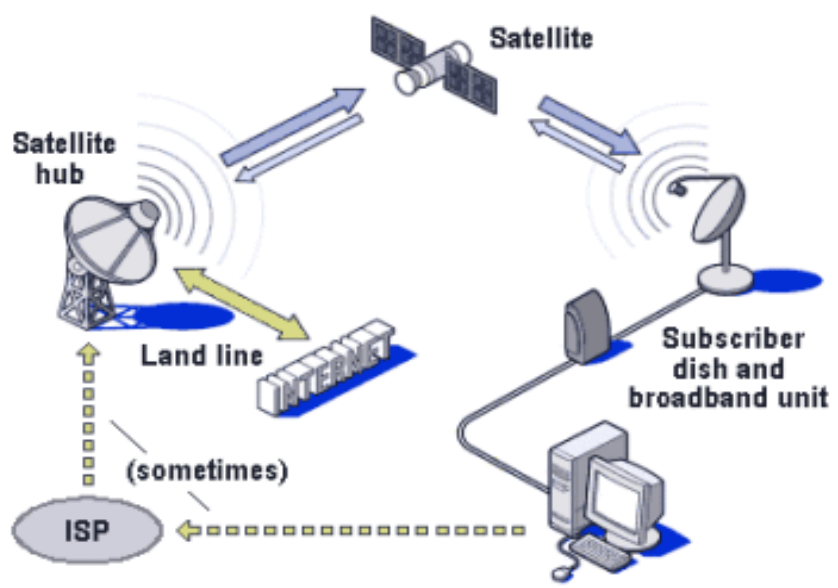

Figure 10. Satelite Broadband 
Application of ISPs in Daily Life

Telkom Speedy ADSL Network

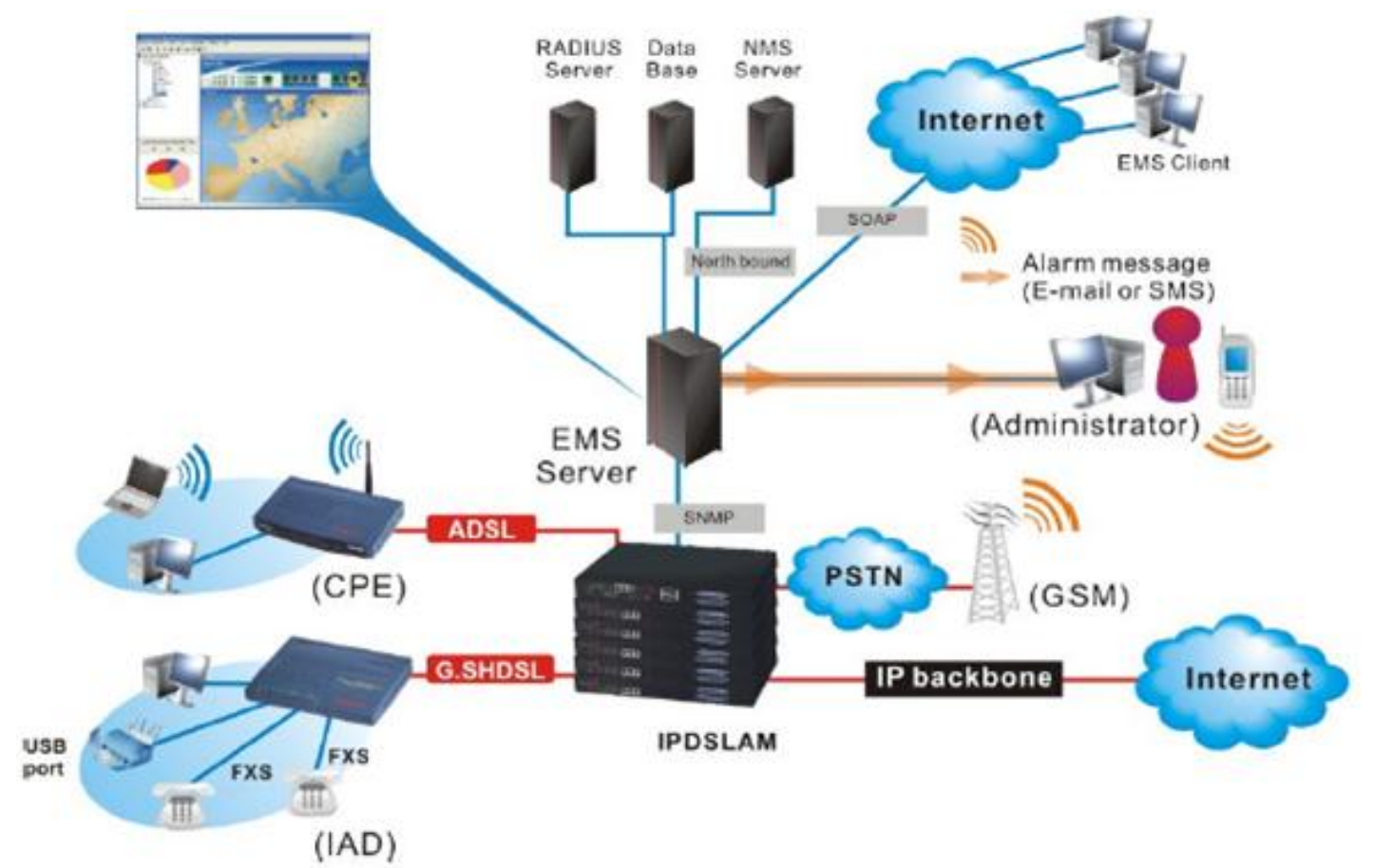

Figure 11. ADSL network

High-level digital data transmission over the telephone line path. Usually abbreviated with ADSL. ADSL is a technology developed modulation with Discrete Multitone (DMT), which enables high data transmission speed ADSL. Simultaneously using regular phone service, ISDN, and high-speed data transmission facilities, such as video. DMT-based ADSL is a transition from copper to fiber cable of the future. This is what makes ADSL more economically used for local phone companies to be able to provide high-speed data services before using fiber optics technology.

ADSL is a type of DSL where the upstream and downstream runs at different speeds. In this case, the downstream is usually higher. The common configuration enables downstream up to $1.544 \mathrm{Mbps}$ (megabits per second) and $128 \mathrm{kbps}$ (kilobits per second) upstream. In theory, ASDL can serve speeds up to 9 Mbps downstream and 540 kbps upstream.

ADSL is a DSL technology that transmits data faster downstream than upstream. Maximum downstream speed is $8 \mathrm{Mbps}$ upstream while the fastest is $640 \mathrm{Kbps}$. The ADSL connection is good up to a distance of about $5 \mathrm{~km}$ from the nearest STO via copper telephone wires. 


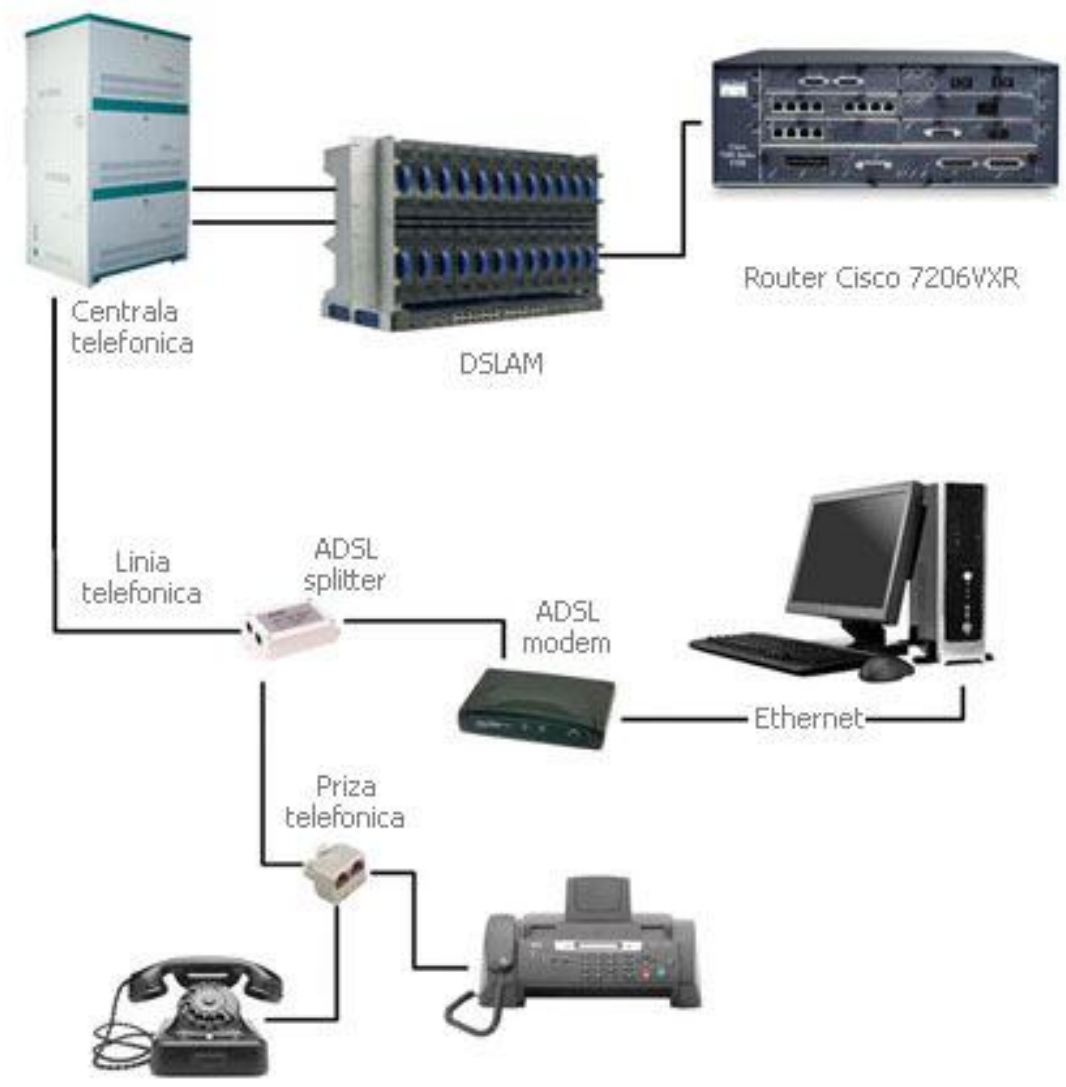

Figure 12. ADSL Network Technology Installation Scheme

As for ways of using ADSL in Indonesia, first of all, we must first have an ADSL device. They have ADSL devices, we have to check for the existence of our home phone number in Telkom Speedy service, whether registered or not. The next thing to note is, how far the distance between substations Telkom with our homes. Because in ADSL, the distance is very influential in internet connection speed. After making sure that the phone number has been registered and the distance has been calculated, we have to do next is the installation of ADSL on the telephone connection. To connect the ADSL to the ' ' line ' ' phone, we use a tool called a [ [ Splitter ] ] or a divider line. ' 'Splitter ' ' is useful to eliminate distractions when we use an ADSL modem. So that later we can still use the internet and answering the phone simultaneously

\section{Conclusion}

ISP ( Internet Service Provider ) is a company or business entity that sells an internet connection or the like to the customer. Many ways used to be able to choose a good ISP as mentioned in the above paper. A lot of software that can be used to connect with one of the Internet with Internet Explorer or can also use the services of WARNET (internet cafes).

\section{Advice}

We recommend that before subscribing to an ISP, select criteria that might be making your connection to the internet faster. 


\section{References}

Fernández, E., Sobrequés, J., \& Schiaffino, A. (1999). Epidemiology and public health journals on the Internet. Journal of epidemiology and community health, 53(8), 510.

Błachnio, A., Przepiórka, A., \& Pantic, I. (2015). Internet use, Facebook intrusion, and depression: Results of a cross-sectional study. European Psychiatry, 30(6), 681-684. https://doi.org/10.1016/j.eurpsy.2015.04.002

Sardini, E., \& Serpelloni, M. (2010). Instrumented wearable belt for wireless health monitoring. Procedia Engineering, 5, 580-583. https://doi.org/10.1016/j.proeng.2010.09.176

Kraus, R., Stricker, G., \& Speyer, C. (Eds.). (2010). Online counseling: A handbook for mental health professionals. Academic Press.

Pereira, P. C. (2014). Milk nutritional composition and its role in human health. Nutrition, 30(6), 619-627. https://doi.org/10.1016/j.nut.2013.10.011

Gackenbach, J. (Ed.). (2011). Psychology and the Internet: Intrapersonal, interpersonal, and transpersonal implications. Elsevier.

Madan, S., \& Bodagh, I. Y. (2002). Dedicated to elderly care: geriatric medicine on the internet. Age and ageing, 31(1), 70-74.

Ustinavičienė, R., Škėmienè, L., Lukšienė, D., Radišauskas, R., Kalinienè, G., \& Vasilavičius, P. (2016). Problematic computer game use as expression of Internet addiction and its association with self-rated health in the Lithuanian adolescent population. Medicina, 52(3), 199-204.

Myers, K., \& Turvey, C. (Eds.). (2012). Telemental health: Clinical, technical, and administrative foundations for evidence-based practice. Newnes.

Neinstein, L. (2000). Utilization of electronic communication (E-mail) with patients at university and college health centers. Journal of Adolescent Health, 27(1), 6-11. https://doi.org/10.1016/S1054-139X(99)00119-6 